\title{
The effects and mechanisms of saikosaponin D improving the sensitivity of human gastric cancer cells to cisplatin
}

\author{
Jianran Hu1,2, Ping Li1,2*, Baozhong Shi², Jun Tie² \\ ${ }^{1}$ Department of biological science and technology, Jinzhong University, Jinzhong, China \\ 2 Department of biological science and technology, Changzhi University, Changzhi, China \\ *Corresponding Author \\ E-mail: hitliping@163.com
}



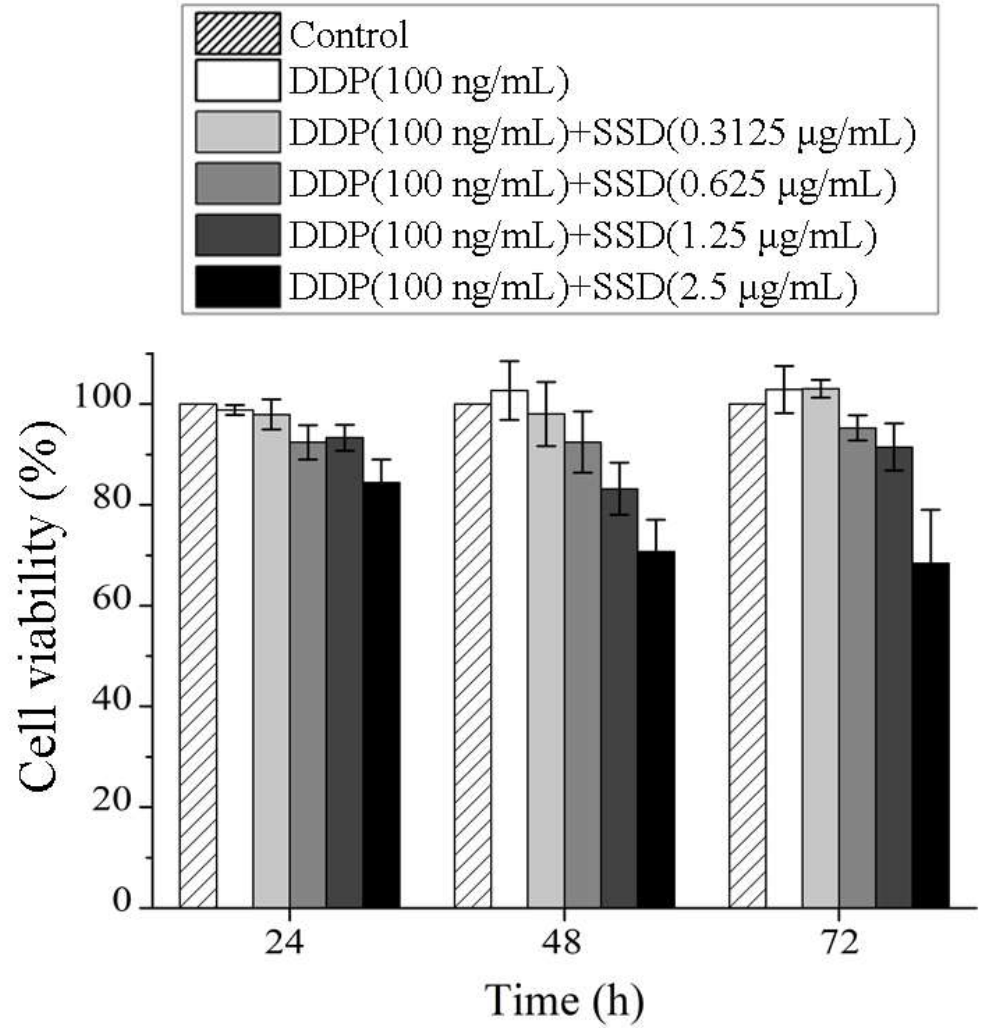

Figure S1. Effects of SSD combined with DDP on GES-1. 

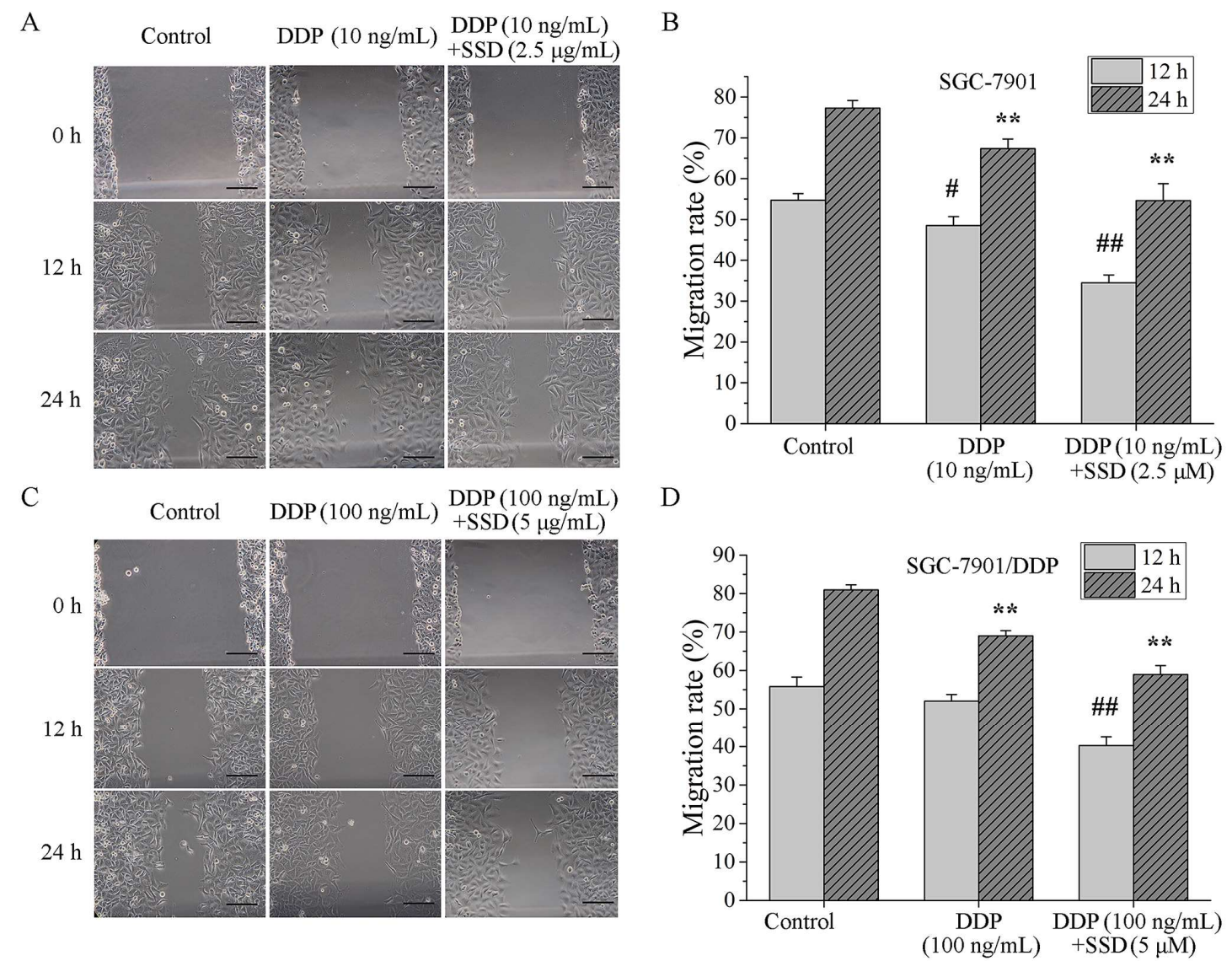

Figure S2. Effects of SSD combined with DDP on cell migration. Wound healing assay was conducted in SGC-7901 (A) and SGC-7901/DDP (C) cells, respectively. The width of the scratch was statistically analyzed (B and D). $* p<0.05$, $* * p<0.01$, compared with control after $12 \mathrm{~h} . \# p<0.05, \# \# p<0.01$, compared with control after $24 \mathrm{~h}$. 